
Manual de Ciencia Política y Relaciones Internacionales / Editores Fabio Sánchez y Nicolás Liendo; autores Sergio Ángel ... [et al.] - Bogotá: Universidad Sergio Arboleda, 2020.

$305 \mathrm{p}$.

ISBN: 978-958-5511-97-2 (.pdf)

1. GIENCIAS POLÍTICAS - MANUALES 2. RELACIONES INTERNACIONALES

- MANUALES I. Ángel, Sergio II. Sánchez, Fabio, comp. III. Liendo, Nicolás, comp. IV. Título

320 ed. 22

\section{MANUAL DE CIENCIA POLÍTICA Y RELACIONES INTERNACIONALES}

(C) Universidad Sergio Arboleda

\section{Editores}

(C) Fabio Sánchez, Nicolás Liendo

Autores

C Sergio Ángel, Rodrigo Losada, José Rivas, Diego Martínez,

Patricia Muñoz, Marcela Valencia,

Fabio Sánchez, Clara Acosta,

Catherine Ortíz, César Niño,

Mario Aller, Jaime Ariza,

Alejandro Cardozo

Asistente Editorial

Camilo González

ISBN: 978-958-5511-97-2 (.pdf)

doi: https://doi.org/10.22518/

book/9789585511972

Primera edición: agosto de 2020

Fondo de Publicaciones de la

Universidad Sergio Arboleda

El contenido del libro no representa la opinión de la Universidad Sergio Arboleda y es responsabilidad del autor.

Licencia de uso:
Diseño y diagramación:

Maruja Esther Flórez Jiménez

Fotografía de la Portada:

Salón Libertador Simón Bolívar.

Créditos: Fotos Institucionales,

Organización de Estados Americanos

(OEA) Washington D.C.

http://www.oas.org/OASpage/Photos/ photo institutional/MNBSBolivar.jpg

Universidad Sergio Arboleda

Calle 74 No. 14-14.

Teléfono: (571) 3257500 ext. 2131/2260

www.usergioarboleda.edu.co

Bogotá, D.C.

Impresión:

DGP Editores.

Bogotá, D.C. 
Capítulo XI

\section{LA HISTORIA \\ EN LAS RELAGIONES INTERNAGIONALES}

Alejandro Cardozo*

\section{Introducción}

Entre 1971 y 1977 se triplicó el personal del Comité de Relaciones Internacionales de la Cámara de Representantes en el Congreso de Estados Unidos, con el fin de imponer control sobre la política exterior de la Casa Blanca. Acaso, se trataba del momento más dinámico de una política presidencialista sobre asuntos internacionales - el contexto de la Guerra Fría así lo demandaba- que alertó al Congreso sobre una desbordada actuación del presidente de Estados Unidos en la política mundial.

La caída de Richard Nixon (1974) permitió que aquella crisis abriera las puertas al poder legislativo sobre las posibilidades decisorias del ejecutivo en los asuntos mundiales. Se aprobaron, a finales de la década, cerca de setenta enmiendas para limitar la conducción presidencial de la política exterior estadounidense. El Comité de Relaciones Internaciones de la Cámara de Representantes estudió cada caso, desde la crisis en Indochina, el conflicto árabe-israelí, las dictaduras en Latinoamérica, las

\footnotetext{
Profesor e investigador del Grupo de Análisis Político (GAP), Escuela de Política y Relaciones Internacionales, Universidad Sergio Arboleda. Correo electrónico alejandro.cardozo@usa. edu.co (iD https://orcid.org/0000-0002-4461-3285
} 
relaciones con la Unión Soviética y China, para sopesar el balance de poder entre el legislativo y la poderosa presidencia; incluso, se llegó a estimar que la Ley de Poderes de Guerra pasara a manos de la Suprema Corte, con lo que la cualidad de comandante en jefe del presidente se puso en duda. Este fenómeno legislativo del equilibrio de poderes en la democracia más antigua y paradigmática de la modernidad, puede explicar el rol que juegan la historia y las relaciones internacionales en la configuración del sistema internacional.

El registro de todos los acontecimientos en las relaciones internacionales (RI) corresponde a otras disciplinas auxiliares de la historia, sin embargo, la capacidad de hacer ciencia histórica partiendo de los fenómenos políticos, diplomáticos, militares, culturales, sociales y económicos que ocurren en el seno de las RI, son competencia de una disciplina que debe anteponerse -en la práctica política y en el ejercicio intelectual- a los dispositivos que toman decisiones en la política exterior de un país.

Así también, las interpretaciones, usos e instrumentalización política de la historia de las RI, es otra constante en los continuos intentos de reconfiguraciones geopolíticas; por ende, es una obligación intelectual de la disciplina discernir estos derroteros a través del rigor científico que debe imponerse en la ciencia histórica.

\section{Los peligros de la analogía y la simplificación histórica en las Relaciones Internacionales}

Pierre Grosser y Valérie-Barbara Rosoux diferencian a la Historia como una herencia "peso", como una analogía útil "ley", como instrumento "elección" y como una anticipación "fe" (Rosoux, 2000). A la hora de emprender un análisis histórico de envergadura, se debe prescindir de la analogía entre procesos a través de la simplificación de los fenómenos y los eventos. Pues la falta de imaginación para comprender un evento nuevo en las RI, puede conducir a una ley de mínima acción y a un automatismo creativo en el análisis, con lo que el historiador de las RI puede terminar comparando las primaveras árabes (2010-2012) con las revoluciones europeas de 1848; o una analogía absurda - pero tentadora- entre la Guerra de los Treinta Años (1618-1648) y el 11 de septiembre de 2011 como el comienzo de una guerra santa. Por el nuevo rol mundial de China, el protagonismo forzado de la Rusia de Vladimir Putin y la retórica de la "América grande" de Donald 
Trump, algunos analistas caen en la tentación de hablar de una nueva Guerra Fría. (Tertrais, 2018, p.18-19).

No solo los analistas de las RI corren este peligro, los líderes mundiales rebuscan el pasado como inspiración y justificación de su política exterior, lo que genera confusión en la opinión pública mundial sobre el desempeño internacional de sus líderes. Hugo Chávez se creyó heredero de la visión continental de Simón Bolívar y Vladimir Putin insiste en Kiev como lugar de nacimiento de la Rusia imperial (celebrando como efeméride rusa el bautismo en el año 988 de Vladimir I en Crimea). Asimismo, cualquier intervención militar a gran escala revive el fantasma de Vietnam o de Afganistán. Es decir, en política exterior la historia es una guía pero también es una limitación.

La utilización de la analogía histórica es una poderosa arma política. Nunca hay neutralidad u objetividad en la elección de una analogía de eventos históricos, porque siempre ofrecerá un reacomodo anacrónico pero útil, de los aparatos ideológicos (Tertrais, 2018, p.21).

\section{Relaciones Internacionales, relaciones interestatales, relaciones trasnacionales}

En Inglaterra, a finales del XVIII se acuña la acepción del término internacional "entre las naciones" para diferenciar la política doméstica -a cargo de las instituciones y autoridades internas- de la política exterior, en manos de la diplomacia, los militares y la seguridad del Estado, es decir, un mapamundi fraguado por los Estados (Neila, 2001, p.18).

El devenir del siglo XX dispuso - por los rigores de las dos guerras mundiales y en buena medida por la coacción aplastante de la cotidianidad política de la Guerra Fría- otros actores periféricos del Estado, que entramaron un diálogo más allá de la estructura estatal, por fuera de las cancillerías y de los comandos estratégicos militares. Esa interlocución política y cultural también perfiló una suerte de relaciones trasnacionales, relaciones transfronterizas entre naciones y pueblos que determinaron un curso de los eventos sin la participación de los Estados, sin ser exclusivamente relaciones interestatales cogiendo el pulso del sistema internacional en dinámicas transfronterizas, y dándole cuerpo a unas RI, en cuanto a decisiones de Estado 
- devenidas de ese diálogo- ${ }^{-}$y generando, al mismo tiempo, problemas ${ }^{-} \mathrm{O}$ soluciones- ${ }^{-}$a temas de seguridad.

Para ejemplificar esto último podemos usar el caso el Congreso Mundial por la Paz y su némesis, el Congreso por la Libertad de la Cultura, ambos coloquios culturales durante la Guerra Fría, llevados a cabo por intelectuales de ambos aleros ideológicos, quienes incidieron en el corto y mediano plazo sobre las decisiones de los sistemas estatales de Occidente y del Pacto de Varsovia.

Los soviéticos fueron pioneros en monopolizar estas iniciativas intelectuales dentro de un ámbito de diálogo trasnacional, a través del primer Congreso por la Paz en Wroclaw, Polonia, en el verano de 1948. Será el antecedente de una sucesión de eventos culturales análogos, donde los soviéticos movilizarán (al margen del Ministerio de Relaciones Exteriores de la URSS) por el mundo a intelectuales, artistas y creadores. Los soviéticos comprendieron el poder de entablar diálogos trasnacionales lejos del rigor y la formalidad de la diplomacia de Estado, para lograr efectos políticos en las relaciones interestatales con Occidente. Andrei Zhdanov, organizador de la Kominform para Europa declaraba que los mejores intelectuales y científicos de Europa pertenecían al Partido Comunista (Stonor, 2001, p.35).

Más allá de la intervención solapada del Kominform o de la CIA -como agentes al servicio de sus Estados- estamos frente a una dinámica por fuera de las relaciones interestatales; es una dimensión de las RI dada por medio del diálogo político-cultural entre los pueblos del sistema internacional durante la Guerra Fría. Estas relaciones-internacionales-culturales fueron prioridad de los Estados en liza ideológica, política y militar desde 1948 hasta finales del siglo XX, que definieron a la Guerra Fría como una guerra cultural (Stonor, 2001, p.51).

\section{La Historia $y$ las Relaciones Internacionales}

\section{Historia de las Relaciones Internacionales como saber híbrido}

La primera historiografía positivista a partir del ideal de "verdad histórica" concedió toda cientificidad a la certeza del documento oficial emanado de la razón política de Estados, gobiernos e instituciones. Así pues, la historia diplomática es un germen de la filosofía positivista, particularmente de su franquicia historiográfica, que analiza el devenir político de los principales 
actores de un sistema internacional: líderes, militares, estadistas y organizaciones políticas en el marco normativo - el derecho de gentes o derecho internacional- de unas interrelaciones dadas más allá de las fronteras nacionales.

Acaso de una forma profesionalizada, tras la debacle de la I Guerra Mundial deviene una disciplina diferente. Suerte de think tanks (como The Royal Institute for International Affairs en Londres y en Nueva York el Council of Foreign Affairs, 1920 y 1921 respectivamente) conformados por académicos, políticos, banqueros y evidentemente diplomáticos, contundidos por la guerra entre 1914 y 1918, deciden crear estos espacios y ámbitos para entender los orígenes de la guerra, las crisis políticas y económicas que alimentaron la desconfianza entre los Estados e idear la manera política y económica de enfrentar nuevos retos durante la breve y nublada victoria. Acaso se trataba de formalizar y volver rigurosa y permanente las tertulias y bailes al estilo del Congreso de Viena en 1821 (Kissinger, 2000), que en el fondo buscaba lo mismo con personajes similares, en el contexto de intereses de supervivencia y supremacía equivalentes. Solo que en estos centros de pensamiento no surgirían automáticamente respuestas oficiales ni mandatos definitivos, como tal vez sí en el congreso vienés; pero sí resultarían consejerías, asesorías y productos intelectuales -publicaciones- sobre el análisis del tiempo presente. Nace entonces la disciplina y un incipiente método de las Relaciones Internacionales.

Este momento, donde se gesta una subdisciplina dentro de las ciencias sociales, es también el momento del giro historiográfico de la primera generación o corriente de Annales, escuela historiográfica francesa fundada por Marc Bloch y Lucien Febvre en 1929. Cada generación de Annales ha planteado "revoluciones" historiográficas y formas metodológicas innovadoras que impactan el mundo académico. Se admiten cuatro generaciones de Annales, e inclusive de una quinta que aún se debate su existencia. Este primer ciclo de los Annales supera o intenta superar el canon positivista que imponía la dictadura del documento oficial, descartando todos los elementos periféricos que de alguna manera daban forma a la esencia de ese documento fragmentario y escaso para explicar causas, precedentes, comportamientos, lógicas, etc., de las acciones del hombre sobre la vida de una sociedad y así tal vez, sobre el sistema internacional.

La epistemología de las RI deseaba desatarse de la camisa de fuerza que podría imponer el derecho de gentes y la historia diplomática para expli- 
car los desastres del sistema económico o los advenimientos de escenarios de ruptura total como la Revolución Bolchevique (Pomian, 1978, p. 115). Esa misma camisa de fuerza se imponía sobre la historiografía precedente; Annales rompe con ella dentro de un horizonte de gran aliento como la "historia total" (Burke: 2007, 12-53) donde todos los factores contaban -especialmente los económicos- para engendrar un proceso del hombre, no solo el político-oficial y/o el diplomático. Asimismo, aunque Francia con Annales pareciera que llegara tarde al problema histórico de la economía, pues el proyecto materialista histórico-dialéctico de Marx en su estudio del capitalismo, logra, sin dudas, una historia económico-política ciertamente global. Asimismo, quienes continúan esa tradición, así sea para criticar los postulados marxianos pero en definitiva, se prolongan por esa línea como Alfons Dopsch, Karl Lamprecht, Werner Sombart e incluso Max Weber.

De esta posible lectura híbrida (añadiendo la lente de tiempo presente de las RI) de la sociedad internacional (este término proviene de la escuela inglesa) surgen las historias de las RI tomando en cuenta todo aquello que Annales -y el materialismo histórico-dialéctico- propone observar -más allá del decreto oficial- donde, como propusimos en la introducción, todo puede valer -ser útil- para advertir cambios y prolongaciones en las relaciones políticas, militares, económicas, culturales y religiosas entre diversos actores internacionales, más allá del Estado.

En El Capital de Marx, la evidencia histórico-política de la cuasi entera anatomía del sistema capitalista se analiza, más allá de la fenomenología económica, desde una visión global, como suerte de RI desde la dinámica de la economía: intercambios entre los imperios marítimos, los choques entre una civilización precapitalista y el mundo mercantil, manifestaciones sociopolíticas en el mundo colonial, estudio de los nichos industriales establecidos y las incipientes formas ancestrales precapitalistas cohabitando con formas modernas de producción.

\section{Un autor que merece apartado: Pierre Renouvin y las fuerzas profundas}

Renouvin (1893-1974) se considera como uno de los pilares fundacionales en el campo de la historia de las RI en cuanto a su monumental obra y, sobre todo, por el uso de una suerte de historiografía total, arropadora, para abor- 
dar cada fase de los procesos del hombre, de la sociedad, de la nación y del Estado en su relación con los otros entes del sistema internacional. Cuando referimos a los procesos del hombre, es la incorporación de la explicación intelectual del sujeto en los procesos históricos. Al respecto, llama la atención la sólida y elocuente explicación de Renouvin sobre el núcleo del nacionalismo y la unificación de Italia: toma en cuenta para este proceso político los poemas del toscano Giuseppe Guisti, los dramas líricos de Nicolini como "impulso a la aspiración de la independencia y de la unidad." Diserta sobre la obra del escritor Francisco Guerrazi, y como su novela histórica recordaba los grandes hechos del pasado italiano con la finalidad de "extraer ejemplos y lecciones para el presente" (Renouvin, 1998: 128).

Plantea que ese movimiento ideológico, constituido por novelistas, poetas e historiadores, daba soluciones al problema de la unidad nacional. Doctrinas que van a ser el germen de la unidad italiana como el neogüelfismo (el Papado y el clero católico como aliciente de la regeneración nacional y la unión italiana) serán expuestas por Renouvin -para determinar hechos políticos y militares futuros- sobre el rol de Italia en la Europa de los nacionalismos nacientes (Renouvin, 1998, p.127-145).

Así también, la instrumentalización de una historiografía total en la obra de Renouvin (1998) es el modelo metodológico de una mirada multifocal, desde varios prismas, para abordar procesos específicos: historias generales de Europa, historias generales de las relaciones internacionales, historias "dedicadas a una índole de cuestiones" (p.5) -historiografía sobre el tiempo y espacio específicos del sujeto que se estudia, sobre los movimientos políticos, sobre la evolución de los nacionalismos modernos, sobre la ideología nacionalista en Europa, sobre el Mediterráneo e Italia, sobre el Atlántico, etc.

Renouvin pertenece a la generación de intelectuales europeos profundamente marcados por la Primera Guerra Mundial (estuvo en batalla y fue herido), circunstancia que lo condujo a un compromiso hermenéutico acerca del sistema internacional y las causas de la guerra. Se debe acotar el hecho de que su obra Historia de las Relaciones Internacionales (siglos XIX y XX) dedica un capítulo a las independencias latinoamericanas, en el cual es sugerente su intento de exponer un solo espíritu político, y digamos epocal, de nacionalismos, independencias y proyectos unionistas en Occidente, donde América Latina también forma parte de ese bloque histórico-político. 
Estamos discurriendo, realmente, sobre un tratado de las RI, una obra de más de 1200 páginas, con extremo detalle y cuidado en las perspectivas historiográficas; con todo y que lo extenso de su objeto histórico le exige al autor sobre lo que en teoría deberían ser visiones generales de grandes procesos.

\section{Algunos obstáculos en el campo}

El debate epistemológico y de método alrededor de la Historia de las RI es prolífero, inacabado y en cierto punto baladí. Es decir, anhela plantear que la evolución de la mirada científica del objeto interpuesta por toda una cuasi infinita constelación de factores que pueden distraer la "verdad" - por subjetivo que parezca- del investigador, es un planteamiento superficial, necio; en las RI no llega a ningún lado, termina por explicar muy poco. El "giro lingüístico", por ejemplo, que duda de la relación del historiador con el documento porque su propia interpretación del mismo ya es un engaño, es una falacia metodológica en tanto y cuanto el conocimiento científico-social, humanístico e intelectual en general, ya viene siendo un aporte desde la -llanaperspectiva acumulativa de métodos, observación, narrativas probabilidades y representaciones. Ese debate, a partir de las propuestas posmodernas que dudan de los datos recolectados por el antropólogo - para proporcionar un ejemplo conmovedor y a la vez patético- pues supuestamente su visión ya está contaminada una vez que él parte de su propia cosmovisión: intereses políticos, económicos, de género y de clase, así como de sus prejuicios; ese tono confuso de condicionamientos epistemológicos y metodológicos ha sido transmitido a la historia-historiografía así como a las RI.

El condicionamiento discursivo sobre la suspicacia acerca del poder como paradigma narrativo ha desbordado el debate. Es lógico pensar que hubo silenciamientos metodológicos por presencia y protagonismo informativo en el documento - pieza de relojería en la ciencia histórica-; la mujer por siglos de patriarcado político y económico no está muy presente en el clímax de algunos acontecimientos -aunque cuando surge este asunto, nos viene a la memoria Olimpia de Epiro, Livia Drusila, Myeongseong la reina Ming, Catalina II, Evita Perón, Indira Gandhi, Margaret Thatcher...-, por ende, hay ausencias en la construcción historiográfica y documental de procesos entre grandes masas, sistemas internacionales, acoplamientos, etc., ¿cómo forzar 
ese eclipse, esa laguna, con una mirada preceptiva, artificiosa, de género en las RI? Es posible, por su puesto, comprender el papel de las sufragistas en el nuevo orden mundial, la apertura del sistema político y de poder, el sistema democrático perfectible, las nuevas fuerzas de pensamiento, nuevas sensibilidades políticas, otra demanda en la construcción de las instituciones, en el diálogo y su tipología, la semiótica del poder partiendo de ahí; en todo caso un hecho determinante, no un factoide (Mailer, 1968) determinado por un debate fútil para acaecer ideología simulada en una corriente del pensamiento y de las ciencias sociales que puede $-\mathrm{y}$ debe- ${ }^{-}$ser acumulativa -incluso desde la misma experiencia- y no rupturista para ensayar con la novedad, o lo que es peor, granjearse un mercado ideológico insustancial.

\section{La mirada de la lente pequeña para el detalle}

\section{Consideraciones sobre el Institucionalismo Histórico en las Rela- ciones Internacionales y el Giro histórico}

Los institucionalistas históricos (IH) consideran en su ensayo de observación, comparativamente, contextos críticos - clivajes-(Ramos, 1997) y procesos de largo plazo para determinar su correspondencia, interconexiones y secuelas asidas en ese comportamiento histórico; mientras que lo usual en la Ciencia Política, por ejemplo, es observar escenarios determinados de manera aislada, seleccionando plazos cortos para el examen de maniobras solo coyunturales, como una expresión única del fenómeno analizado. Aunque el IH es uno de los tantos enfoques implementados en la Ciencia Política empírica, su fusión metodológica con el método histórico-historiográfico con las RI (la llamada Historicist Historical Sociology) puede dar resultados, o al menos, serán los resultados de planteos teóricos sustentados sobre una base empírica sólida de la historia-historiografía, como la investigación documental de momentos-episodios-acontecimientos acerca de la duda (investigación) de fenómenos a largo plazo.

Así como los IH consideran en conjunto las "agendas sustantivas, argumentos temporales y atención a contextos y configuraciones" (Pierson y Skocpol, 2008, p.9) para contribuir sustantivamente a la comprensión de, por ejemplo, regímenes políticos autoritarios; la historia y la sociología histórica aplicada en el análisis de las RI ha producido grandes hitos en la disciplina 
híbrida: The Modern World-System (1974, 1980 y 1989) de Immanuel Wallerstein. Una fusión de ciencias, métodos y disciplinas positivista, materialismo histórico dialéctico, Annales ("Historia total"), y varias teorías entonces determinantes en el mundo Guerra Fría, como la teoría de la Dependencia. Su mirada viene desde el orden feudal, las revoluciones burguesas y sus correspondientes antagonismos violentos en la Historia.

Asimismo los IH se preguntan por qué las revoluciones aquí y no allá, ayer y no hoy; por qué democracias duraderas y estables en unos países y en otros autoritarismos populistas; por qué Estados Unidos logró esa excepcional fórmula de un Estado de características institucionales a diferencia de las craqueadas instituciones hispanoamericanas. Son solo preguntas con respuesta en una poderosa episteme histórica. A pesar de lo robusto que puede ser este método híbrido - ciertamente exitoso en la Ciencia Política como en las RI- se ha señalado de "tempocentrismo" cuando no se diferencian las estructuras de antes con las actuales, construyendo erróneamente visiones isomorfas, bajo la ley de la historia cíclica (Hobson, 2002, p.118). Esta anomalía del análisis sobre la base epistemológica de la Historia puede generar comparaciones a la fuerza. El otro extremo es el "cronofetichismo" que es tan o más peligroso, cuando trata de tomar el tiempo presente como único, inconexo, descontextualizado, ajeno al pasado, a la Historia como evento y a la historiografía como sistematización intelectual y metodológica de aquellos. Una suerte de inmediatez incesante ajena a los cambios.

Hay autores proponiendo que la sociología histórica en las RI no es una historia de las RI (Cascante, 2015), pues cuando se complementan, no son lo mismo; que en todo caso las RI otorgan a la historia-historiografía utilidad conceptual, y en el otro sentido esta brinda a las RI interconectividad de hechos, explicación multicausal; en pocas palabras: contextualización. Nosotros podríamos decir que la evidencia es tan abrumadora que nadie las confunde (desde la estética narrativa, hasta la problematización de cada caso); empero, sí podemos insistir metodológicamente que el IH y su rastreo de procesos es -aunque antigua forma histórica-historiográfica- una instrumentalización útil - al menos saber que existe y que es legítima en la episteme de la Ciencia Política- para el investigador de las RI. El historiador de las RI hace historia con métodos, enfoques y corrientes propias de la historia-historiografía y su insumo, eventualmente, puede ser producto del análisis de las RI. 
Las RI habían descubierto que el método historiográfico les era útil desde el fin de la II Guerra Mundial, para advertir en la Historia una evolución natural de las perdurables preguntas del porqué de las crisis. No obstante, nuestra insistencia radica en la posible metodología y práctica del IH como su proceder continuo de un movimiento contante de atrás y adelante entre los casos comparados, cuestionamiento o hipótesis. De hecho, problemas provenientes de desviaciones, sacudidas y vaivenes del mundo real que no han sido explicadas previamente - por obvias o por su zona gris- o, lo más sugerente, que los "patrones empíricos van contra la sabiduría popular o académica" (Pierson y Skocpol, 2008, p.11).

No es forzado buscar una afinidad teórica y mucho menos metodológica de este enfoque puro de conductistas y comparativistas de la Ciencia Política, empero, vale dejar atado, a modo de prueba, uno de los temas fructíferos del IH: el desarrollo de los Estados de bienestar moderno (Amenta, 2000) que ha permitido el diálogo entre teóricos normativistas (seguridad, igualdad, libertad, democracia, leyes, constituciones) e IH. Ahora bien, qué escamoteo interdisciplinar puede haber si se reconstruye los Estados de bienestar desde la visión de sus relaciones entre ellos (relaciones entre los Estados de bienestar) como a) Estados sociales de derecho propiamente b) modelos económico-políticos similares, agendas electorales parecidas, democracias lidiando con contradicciones equivalentes c) con una historia semejante de autocracias nazifascistas o contra el nazifascismo en el contexto de las guerras europeas d) que se están desintegrando ante la amenaza de la migración y del populismo de las extremas izquierdas y derechas. Los IH ya son comparativistas en la escena histórica-historiográfica por el rastreo de procesos históricos, las dimensiones históricas de la causalidad, (Rueschemeyer y Stephens, 1997; Mahoney, 2000) por ende es posible otra hibridación en los enfoques que puedan ser de utilidad para las RI.

\section{El método historiográfico en las Relaciones Internacionales}

\section{¿Elíxir solo para realistas?}

El historiador de las RI, o el politólogo internacionalista analizando la historia-historiografía, no debe -ya lo dijo Bloch (2001) - alejarse de la confusión y fatalidades del presente, (p.70-71). En ese sentido podemos ver que, 
desde el método y a partir del análisis, es la corriente realista de las RI la que se adhiere al método historiográfico para poder encontrar sentido a su análisis fundamentado en el insumo, a modo de materia prima, que la historia-historiografía dispone.

La juventud de la disciplina de las RI no ha sido obstáculo para que sucedan diversas escuelas y corrientes de pensamiento y análisis. Así también esto ha sido representado por un escarceo de debates no siempre provechoso (Dougherty y Pfaltzgraff, 1981; Mesa, 1980) desde la entrada en la contienda del subjetivo foco postmoderno (el giro lingǘstico) en las RI en particular, y en las ciencias sociales en general. Ya hemos mencionado alguna disquisición al respecto, empero, para avanzar, situemos el epígrafe en los que en efecto llegaron a alguna parte. El debate genésico, entre idealistas y realistas (cuestión que pudo provenir de la visión política del mundo del presidente Wilson, versus el desencadenamiento de los eventos que hoy son las historias de las guerras mundiales y de la Guerra Fría) es el nacimiento de la polémica entre dos cosmovisiones, y de la misma disciplina de las RI: idealismo y realismo (Carr, 2004; Morgenthau, 1972 y Waltz, 1959). En la prolífera década de los sesenta el debate se forjó entre tradicionalistas y behavioristas, para dar paso a la lucha de miradas entre globalistas y realistas.

Las resultas de la Guerra Fría -el único conflicto cabal y cumplidamente global-(Cardozo, 2019; Gaddis, 2011; Carr, 2004, Taylor, 1996) dio la razón a los realistas - con apelativos como neo, nuevo o estructurales- (Keohane y Nye 1973; Keohane, 1984) para establecer con su visión de las RI un "núcleo", punto desde el cual se debe avanzar en la disciplina: "El realismo es un componente necesario en cualquier análisis coherente de la política mundial porque la atención que presta al poder, a los intereses y a la racionalidad es crucial para comprender el tema" (Keohane, 1983, p. 504). Los acontecimientos históricos -y la subsecuente producción historiográfica- de la Guerra Fría lograron que el modelo teórico realista de Hans Morgenthau ${ }^{1}$ se trasformara en un paradigma de las RI. De hecho, alrededor suyo se estableció en la década de los años ochenta un séquito de realistas estructurales,

Scientific man vs. Power Politics (1946), Politics among Nations (1948) y In defense of National Interest (1951) destacan entre más de trescientas obras desde 1929 hasta principios de la década de los ochenta. 
bebedores directos de su elíxir, autodeclarados discípulos de Morgenthau como Robert Gilpin (Gilpin, 1984, p.300).

Uno de los ejes del realismo morgenthauniano es el Estado nacional -así como el estadista- como el lugar donde se toman las decisiones de la política exterior de acuerdo a su supervivencia e interés nacional (estatocentrismo), y como tal, el Estado es un producto de la Historia, situado - para el análisis y la comprensión de su acción- en unas coordenadas históricas que lo determinan $^{2}$.

Un germen de filosofía política también afecta la cosmovisión del realismo morgenthauniano en cuanto se define, por ejemplo, a través de la doctrina hobbesiana respecto al papel del Estado dotado del poder supremo -y suficiente- como para garantizar la seguridad de sus fronteras -territorio nacional-, el orden y la paz. El Estado será entonces un actor racional de las RI, en un contexto donde estas son de naturaleza conflictiva (por el carácter anárquico de las RI así como el apartamiento entre política interior y exterior) y el poder como único objetivo de la acción política -realismo político-Asimismo, como indicamos antes, el estadista para Morgenthau es la fuente de la decisión: a diferencia del neorrealismo de Waltz, Morgenthau no personifica al Estado ni lo convierte en una máquina perfectamente coherente.

La pregunta del realismo es ¿cuáles son los orígenes racional e históricamente reconocibles que posibilitan los períodos de paz o de estabilidad? Por otro lado ¿qué llevó a Morgenthau (también podríamos referir a Spinoza, Hobbes, Maquiavelo o al coetáneo de Morgenthau, Niebuhr) al "pesimismo antropológico" como motivo racional explicativo de las RI? La respuesta es la historia-historiografía. Todos los modelos para aseverar los concluyentes y acaso indefectibles desenvolvimientos de las RI durante la Guerra Fría -con un desenlace final, acaso menos ajustado a la teoría en 1989 y 1991- que podrían seguir explicando - con sumo cuidado sobre las analogías simples- el

\footnotetext{
En el calor de la Guerra Fría, Morgenthau incorpora la cualidad de cambio del Estado histórico, afectado por otros elementos que pueden proscribir su existencia, respecto, evidentemente, a la forma de organización política del poder en las RI. Para él, un nuevo factor que podía afectar la existencia histórica del Estado serían las armas nucleares y la rivalidad atómica entre Estados Unidos y la Unión Soviética, contexto que podría convertir al Estado nación en una forma política obsoleta (Morgenthau, 1962, p.76).
} 
orden internacional en el s. XXI, provienen del consumo metodológico de la historiografía.

Las diferentes fases de la Guerra Fría que pivotaron entre la guerra coreana en 1950, la crisis de los misiles en Cuba 1962, hasta la Détente, pusieron a prueba el modelo realista; aparentemente la seguridad nacional no era el núcleo de la "segunda guerra fría". Factores como el protagonismo de los países no alineados, la nueva diplomacia petrolera y la pérdida coyuntural de concentración de poder de ambas potencias - cuando los aliados respectivos pugnaban también fichas dentro del tablero- hicieron que la novedad realista perdiera foco. Habría que superar el breve instante de expectación unipolar de los noventa, para entrar en otra fase del análisis realista y así abordar fenómenos como la yihad, nuevos bloques tercermundistas de revisionismo político internacional (Unasur, BRICs), el crimen organizado, la migración, el euroescepticismo, etc.

La expresión clásica del método historiográfico en el marco de un análisis realista está en La crisis de los veinte años de Edward Hallet Carr, quien logra por vez primera diferenciar la corriente realista de las utópicas (como el idealismo) en el contexto de un ensayo de corte historiográfico para el beneficio de las RI. Carr plantea que la demanda de resultados de las RI fue notable tras la gran guerra de 1914, cuando ya era irremisible un análisis y estudio específico de la realidad política internacional como fórmula de elucubración respecto a qué y cuáles circunstancias eran necesarias para evitar otra guerra de semejantes dimensiones; Carr concluye que la gran guerra de 1914 a 1918 dejó en evidencia el cambio de estilo de conflagración: ya no era cosa de soldados profesionales, la magnitud del conflicto afectaba sobre todo a la población civil, por ende, la guerra ya no sería un asunto que podía dejarse solo en manos de "diplomáticos profesionales". La penetración de los hechos sobre el desiderátum era un grave error, y había que dar por terminado el análisis basado sobre ideales utópicos y morales (Carr, 2004, p.34-38).

\section{Path dependency o histéresis en las Relaciones Internacionales}

Acaso sea otro préstamo del IH, sin embargo, como lo esbozaremos aquí parecerá una propuesta enteramente ensayística para continuar girando alrededor de la historia-historiografía en las RI, y algunos agregados 
metodológicos para la hibridación de este enfoque. Abordemos, por ejemplo, el problema de los nacionalismos contemporáneos y la incapacidad de la desambiguación con las izquierdas locales a pesar de que el "nacionalismo" teóricamente reacciona contra la izquierda, pues esta es internacionalista y aquellos son conservadores y chauvinistas. No obstante, tenemos en regiones comparadas como América Latina (región independiente y con repúblicas en toda la ley desde el s. XIX), los países árabes y África (con procesos de descolonización solo hasta el fin de la II Guerra Mundial) un path dependency de rebuscar y organizar en y desde sus movimientos políticos anticolonialistas, procedimientos revolucionarios de la izquierda marxista-leninista.

¿Cómo se podría comprender los fenómenos similares y sincrónicos nacionalistas y anticolonialistas, con las guerrillas, frentes de liberación nacional y luchas armadas latinoamericanas? Una región es libre del control de toda metrópoli europea desde las dos primeras décadas del s. XIX, y otra apenas lo es desde mediados del s. XX por el reacomodo de fuerzas coloniales al nuevo orden de posguerra que trata de aplicar Estados Unidos como nación anti-colonialista: "la posición de los Estados Unidos como la más fuerte de las potencias anticoloniales es de incalculable valor para el Mundo Libre (...) Así, había que cuidar la posición moral de los Estados Unidos más que el Delta de Tonkín; de hecho, más que toda Indochina.” (Bragg, 1981, p. 119-120). Las independencias de las nacientes naciones árabes y africanas no llegaron a su emancipación colonial por guerras de independencia sostenidas, y menos todavía por medio de la lucha política y militar de líderes como Simón Bolívar, que a la vez que militares, logran una teoría y praxis de la independencia a lo largo de su obra política, epistolar e inclusive, legal-constitucional.

La historia de las RI explica que la independencia de América Latina es la sincronía de los eventos en Europa, sobre todo en España con la invasión napoleónica, la rebelión de los americanos criollos y la gesta militar de Bolívar y San Martín; más adelante la revolución liberal en la misma España dio el tiempo suficiente para el reacomodo de los independentistas en América hicieran su estocada final, toda vez que la España liberal se enfrentaba con la guerra santa que declararon los católicos hasta el regreso de Fernando en 1823 (Renouvin, 1998, p. 69). 
América Latina podría tener para los años de los nacionalismos africanos y árabes, una élite política robusta, con 150 años de independencia y proyectos republicanos, así como el tiempo suficiente de haber creado una cultura política liberal republicana y en algunos casos, democrática. El Medio Oriente y África apenas habían tenido un modelo político desde la metrópoli colonial, acerca de la naturaleza deliberativa de un parlamento representativo, un sistema democrático e instituciones liberales; sí, acaso alguna parte de la élite local de las antiguas colonias se formaba política e intelectualmente en la metrópoli (sobre todo los provenientes de los territorios franceses y de la India británica) sin embargo, este hecho no puede compararse con siglo y medio de instituciones latinoamericanas. No obstante, es llamativa la sincronía ideológica de Latinoamérica con África y los países árabes, dentro de los credos nacionalistas y revolucionarios, combinados con la ideología marxista-leninista desde 1950 en adelante.

La histéresis podría explicar que la formación de una lógica anticolonial tercermundista se combate desde las élites con la ayuda -durante la Guerra Fría- de Estados Unidos, y esa ayuda es entendida (en centros de ideologización de partidos políticos, universidades y organizaciones culturales) en América Latina como una agresión imperial directa de Washington contra el país - subterfugio del subdesarrollo, además-, y no como el mecanismo de defensa de las élites locales frente a la inestabilidad y para lograr gobernabilidad. Esa política retroalimenta el sentido nacionalista de los revolucionarios, no el sentido revolucionario propiamente internacionalista; el nacionalismo árabe sufre -a pesar de las inmensas diferencias estructurales en ambas regiones - el mismo fenómeno de hípernacionalismo antiimperialista, pero en ningún sentido, un internacionalismo revolucionario como dicta la doctrina marxista-leninista. Un path dependency anti-Estados Unidos en el contexto de disputa $-\mathrm{y}$ defensa de elites locales y empresas- por aquellos espacios (del Medio Oriente, anticoloniales) contra, por ejemplo, la Unión Soviética, igualmente imperial pero internacionalista. El mismo path dependency de América Latina para sus relaciones políticas y culturales con Estados Unidos (Kozel, Grossi, Morioni, 2015) y sus aliados, y con la Unión Soviética y sus satélites.

Como lo explica Henry Kissinger de cara a la lucha anticolonial indochina, la cual deriva en la guerra de Vietnam; Dulles y Eisenhower asumían 
que el colonialismo y el comunismo eran "males gemelos" (Kissinger, 2000, p. 628), es decir, tras un proceso venía el otro, después de una hostilidad que podía tener orígenes solo políticos, germinaba una fórmula de guerra anticolonial y antiimperialista construida por una retórica marxista-leninista, en la que América Latina asumió - sin correspondencia histórica- un path dependency sugerido por lejanos escenarios de la Guerra Fría.

Otro ensayo se puede probar en el estudio de las relaciones civiles y militares en América Latina, donde el path dependency establece ubicar a los militares en el eje ideológico $x y$ hacia la derecha. Ha sido en este caso un path dependency que ha hecho extraviar muchos resultados en el análisis de caso regionales como el de Venezuela y Cuba y la impronta de los militares en la conformación de un autoritarismo competitivo.

La literatura previa, resultado de una fuerte trayectoria dependiente sobre el militarismo en Latinoamérica, sigue insistiendo que Venezuela padece un autoritarismo militar, por la vía de un grupo pretoriano que controla al país. Con ello desestiman lo obvio, que se trata de una poderosa fuerza civil nucleada en un partido único (partido-Estado) la que ha venido interviniendo y desmantelando las Fuerzas Armadas del país (Mijares y Cardozo, 2020). Sin embargo, el path dependency ha dictado desde la mirada de las dictaduras del cono Sur (Videla, Pinochet, Stroessner, Galtieri, etc.) que toda dictadura militar en la región es de derechas, desestimando, por ende, la larga y vigente dictadura militar cubana. Esto último ocasiona otro problema: que entonces Cuba no padece una dictadura militar, sino una revolución fundada por los guerrilleros triunfadores de Sierra Maestra.

Macabra tergiversación de la historia contemporánea latinoamericana y del Caribe pues, precisamente, esta poderosa trayectoria dependiente (hilada también por un aparato cultural muy robusto y sistemático) no permite la comprensión del fenómeno de control militar sobre la población civil, dado que la autocracia unipartidista asamblearia de Cuba no es presidida por militares clásicos, de formación castrense tradicional, sino de corte revolucionario, rompiendo con la convención simbólica de las viejas dictaduras del cono Sur durante la Guerra Fría latinoamericana. Será así de complicado tipificar, en un futuro, al régimen político venezolano, pues el path dependency ha obligado a los militarólogos venezolanos notar - confusamente- una fuerte presencia pretoriana en el poder, cuando lo que está en curso es un 
desmantelamiento de las Fuerzas Armadas para incubar en el gobierno y en el control sobre la población, una milicia civil (Milicia Bolivariana) profundamente ideologizada y comprometida políticamente con la nomenclatura chavista del chavismo-madurato, con directrices de acción y desempeño cubanos.

Este último ensayo metodológico -a modo de ejemplo- nos invita a estudiar las RI entre Suramérica y el Caribe, y entre Suramérica y Centroamérica en el marco de la historia de las dictaduras, autoritarismos y revoluciones del s. XX y s. XXI, con el cuidado analítico requerido para no sesgar los resultados ante el path dependency de las relaciones civiles y militares, aplicado y arraigado durante décadas de estudio de casos regionales comparados. Vale recordar la advertencia sobre los peligros de la analogía y la simplificación histórica en nuestra introducción al capítulo.

\section{Una propuesta de método historiográfico para las Relaciones Internacionales}

The best way for a neoclassical realist researcher to be certain that he/she understands the reasons why state decision makers took the policies that they did, therefore, would be to consult primary sources -such as government documents, memoirs, speeches, decision-maker interviews, and oral histories - in addition to secondary sources.

Ripsman, Norrin M., Jeffrey W. Taliaferro, and Steven E. Lobell. Neoclassical Realist Theory of International Politics (2016)

A lo largo del capítulo hemos aspirado llevar al lector desde el principio del mismo debate de la historiografía, hasta los análisis mixtos para observar la utilidad del método ${ }^{-} \mathrm{O}$ del foco- ${ }^{-}$al momento de realizar conjeturas de procesos largos y medios en casos de estudio de las RI.

Propondremos en este apartado final un método historiográfico para las RI, comenzando por la formulación de preguntas de investigación al azar con el fin de demostrarle al lector la vialidad de una investigación. Articularemos, a modo de ejemplos de estudio de casos, posibles problemas de investigación en nuestro método, comenzando por los atajos de búsqueda archivística para los documentos centrales con el objetivo de su examen y análisis en virtud de la pregunta de investigación. Asimismo, la identifica- 
ción y búsqueda de documentos periféricos y, finalmente, culminar con la construcción de un aparato crítico.

\section{a) El archivo}

En este punto conclusivo del capítulo y del libro, vamos a proponer un método de análisis a partir de fuentes de primera mano, tanto para hacer historia de las RI como para el análisis propiamente, sobre la base de procesos políticos, económicos, sociales y culturales de un período.

Nuestra propuesta en este capítulo es directamente con archivos nacionales que tengan acceso directo en la WEB, con lo cual, el investigador y/o analista de las RI, podría llevar a cabo una recolección de datos desde cualquier punto de su zona de producción académica.

La Unión Europea en el marco de su proyecto europeísta, ha enlazado grandes repositorios de archivos nacionales, regionales y locales, acompañados con una interfaz de datos a gran escala (artículos, entradas a repertorios y compendios nacionales, municipales y locales), como es la portentosa galería Archives Portal Europe (http://www.archivesportaleurope.net/home). El método de delimitación del problema y de la búsqueda es similar a cualquier otro de investigación científica en las ciencias sociales: ¿cuál es el problema de investigación? Supongamos "crisis migratorias y su impacto en las RI europeas" (tema que está definiendo el fututo de Europa); en la barra de búsqueda simple tipiamos "migración" + "Europa". Hecho esto, se desplegará una ventana de opciones: país, fechas, tipo de documento, este último recurso es esencial para demarcar el tipo de análisis histórico (político, económico, cultural, religioso, social...), dado que pueden ser fuentes o fondos documentales (diplomática, estatal, opinión pública, etc.), pues el portal otorga la posibilidad de "tipos de fecha", es decir, una delimitación tiempo/espacio donde el "tiempo" va a determinar los ámbitos de la investigación (espacio geográfico o geopolítico, contextos en "tiempo político" como la Inglaterra del Brexit, por ejemplo, o el partido escocés europeísta de cara al continente, pero separatista de cara a Londres). Del lado derecho habrá opciones de búsqueda, dentro del mismo término, empero más intuitivas: "migración" + "Europa" en tanto "resultados en contexto"; "resultados que coincidan con al menos un término"; "solo material que contenga objetos digitales". Es un motor de búsqueda, como la mayoría, que puede ser intuitivo en la medida que se sepan hacer preguntas. 
En esta búsqueda, como hemos visto hasta ahora, es más bien intuitiva; arrojará estos resultados básicos de acceso a piezas documentales/fuentes de información por países: Portugal (6.399), Alemania (4.872), Suiza (1.294), Suecia (1.139), Países Bajos (445), España (352), Multinational institutions (257), Noruega (169), Austria (73), Francia (69), Dinamarca (47), Reino Unido (45), Islandia (21), Bélgica (4), Finlandia (4), Irlanda (1), Polonia (1), Eslovenia (1). Cada país puede desplegar una pestaña de jerarquía de búsqueda inferior: sus archivos donde se contiene el issue "migración". Por ejemplo, Alemania ofrece para investigar el tema: el Staatliche Archive (con 4.310 documentos), el Kommunale Archive (380), el Archive der Hochschulen sowie wissenschaftlicher Institutionen (78), el Kirchliche Archive (50) Parlamentsarchive (50), y el Archive politischer Parteien und Verbände (con 46 documentos respectivamente). En todos los archivos anteriores hay la cantidad de documentos sobre "migración" que se refieren hallados en la búsqueda. Dependiendo de la gestión documental de cada archivo, podemos tener acceso digital a las fuentes o no, sin embargo, tenemos acceso a la ficha descriptiva y la cota documental (colección, legajo, página). En buena parte de estos archivos europeos es suficiente escribir una carta para solicitar los documentos de interés -en caso de que no estén digitalizados y expuestos en la red-, pagando una cuota de servicios.

La interconexión en el ámbito de búsqueda archivística europea es amplia. No obstante, si la investigación amerita un enfoque atlántico, recurrimos dentro de esta red documental a países con fuerte vocación atlántica, histórica, política y cultural como España, Italia o Irlanda. Ensayamos con The National Archives of Ireland (https://www.nationalarchives.ie/) hacemos una búsqueda basándonos en un atajo histórico: el fuerte lazo histórico que une Estados Unidos con Irlanda; empero, no desde la mirada obvia como el tópico de "migración" de irlandeses a Estados Unidos, sino algo más poderoso en el estudio de las RI. En una búsqueda simple, intuitiva, tecleamos "United States"+ "Europe" + "cooperation"; resulta: European Political Cooperation: special aspects of United States of America-Nine [European Communities] relations. Una ficha documental que está guardada en la colección (o fondo) del Department of Foreign Affairs de Irlanda, con un rango temporal que va desde 1973 hasta 1975. Este elemento puede ser el inicio para una investigación versada en cooperación para la seguridad hemisférica occidental (IRA, 
lucha armada, lucha antiterrorista, cooperación militar y cooperación económica, etc.) en el marco de la Guerra Fría.

Sigamos en el recuadro epistemológico de la Guerra Fría, y pasemos al otro lado atlántico: un portal que puede sugerir grandes cualidades en la búsqueda, por su robusto repositorio, además de su eficiente algoritmo de búsqueda es el National Archives de Estados Unidos, (www.archives.gov), el más completo para la investigación documental en las RI. No solo por tratar temas nodales en las RI, que la mayoría se cruza en algún momento con Washington, sino por su calidad de digitalización y clasificación de tipos documentales. La herramienta de búsqueda del National Archives es tan intuitiva como el mismo Google, toda vez que se haga la búsqueda, se puede precisar en "Everything", "Archives.gov", "Images" y "Presidential Libraries", esta última particularmente útil para el siguiente paso en la propuesta metodológica.

El solo hecho de tipiar el tema de interés, de ahí en adelante el motor de búsqueda dispensará una serie de documentos (no solamente digitales, sino transcripciones enteras), evidentemente, siempre y cuando no sufran el veto de "Classified information", "Confidential" o el cinematográfico -tanto real"Top secret", que cumplen -como en la mayoría de políticas archivísticas-los años de desclasificación, dependiendo de la sensibilidad de la información del documento.

Hagamos el ensayo con una búsqueda general del Grupo Contadora, para estudiar 1) un capítulo de las relaciones interamericanas 2) durante el conflicto centroamericano 3) desde la mirada de Estados Unidos, 4) en el contexto de las RI durante la Guerra Fría. Una búsqueda básica inicial en National Archives produce 178 resultados. Se analiza la calidad informativa y la pertinencia de cada resultado. Uno de los primeros hallazgos es sugerente: "Records of the Special Assistant to the Secretary of State on Soviet Affairs 1977-1981". Entre otras cosas, incluye la ubicación de materiales como, citamos: "Telegrams, itineraries, memorandums of conversation, correspondence, memorandums, drafts, reports, background and briefing materials, documents, and other material relatlng to U.S. policies in Central America and the Contadora process". Este material desclasificado -se señala- es de Richard Fairbanks, quien fue nombrado por Ronald Reagan como ambassador-at-large, el más alto rango del servicio exterior estadounidense, para asuntos cen- 
troamericanos. Como se lee en el documento descriptivo, la colección de informes, borradores, memos, etc., sobre el Grupo Contadora (1981-1985) es considerable. En el marco de la Guerra Fría, la crisis centroamericana fue, acaso, de los últimos vórtices de conflictividad este-oeste, donde Contadora fue determinante como hoja de ruta para salir de la crisis. Por lo que con la calidad de la información que nos ha sugerido este primer examen archivístico, ya se podría emprender un itinerario de investigación viable.

\section{b) Una bibliografía peculiar: memories}

Una vez que se tenga un dossier documental importante, que describa los acontecimientos desde fuentes de primera mano -la materia prima-, se emprende el proceso de identificación de los actores esenciales de ese caso de estudio. Siguiendo con el mismo ejemplo del Grupo de Contadora, se hará un clásico arqueo bibliohemerográfico para determinar los presidentes y líderes políticos de ese momento: los presidentes de Venezuela, Colombia, Panamá y México. Los protagonistas de la Historia suelen tener memorias; cerca del final de sus carreras políticas emprenden ese ejercicio personal para dejar por escrito su legado.

Es esencial hallar esta bibliografía y leer no solo el capítulo dedicado -en este caso- a Contadora, sino buena parte de esas memorias para comprender al personaje en clave oterguiana: al hombre y sus circunstancias. Asimismo, las memorias - o autobiografías- de los jefes del grupo salvadoreño de guerrillas Farabundo Martí, de los protagonistas del sandinismo nicaragüense, del premier sueco Olof Palme, Gabriel García Márquez -sus recuerdos y crónicas del momento de Contadora como observador-, del diplomático mexicano Alfonso García Robles y la también premio Nobel, Alva Myrdal. Es esencial, en este estudio de caso, leer las memorias de Ronald Reagan, Una vida americana (1988), asimismo las de su esposa Nancy, My Turn (1989), por su peso específico en la construcción de la cultura política del presidente, así como en sus decisiones con amplia repercusión en la política exterior de Reagan.

En National Archives, como acotamos antes, hay una posibilidad de búsqueda en "Presidential Libraries", donde reposa vasta información bibliográfica de cada presidente estadounidense (muchos de ellos como legado, dejaron bibliotecas y archivos personales a modo de fundaciones en sus pueblos de origen, con el material histórico que les correspondió en sus respecti- 
vas eras, sus momentos claves durante el mandato, así como memorias, libros especiales sobre lo que consideraron sus mayores logros.

En este punto, serían muy recomendables las memorias del histórico embajador soviético, Anatoly Dobrynin, In Confidence (1997), pues se trata de la mirada excepcional de quien llevó la diplomacia soviética en Washington durante toda la Guerra Fría.

Estamos ante un material documental periférico que otorga claves - menos subjetivas de lo que puede pensarse- políticas y sicológicas devenidas, por ejemplo, del anécdota, pero en ocasiones resultan más cercanas a la realidad de un momento - el momento decisorio-, que el documento final del ejercicio diplomático y de la dinámica oficial del poder; la idea de este método es complementar visiones que en el marco de lecturas más amplias, se acoplan y complementan, pero nunca se repelen. Insistimos en que las memorias y los ejercicios autobiográficos los clasificamos en este método como documentación periférica, pero no como mera bibliografía, pues el tratamiento debe hacérsele como a un documento: interrogarlo. La bibliografía es el armazón donde podrá encajar - o no- la información y datos del archivo y las memorias.

\section{c) E1 aparato crítico}

En este sentido, y siguiendo con el ensayo metodológico sobre el Grupo de Contadora, en el marco de las RI en la Guerra Fría, es cardinal trabajar los libros sobre el proceso. Una revisión exhaustiva bibliográfica sobre el Grupo de Contadora, incluyendo desde monografías y artículos especializados, hasta tesis de maestría y doctorado. El arqueo de prensa es fundamental, se trata de una suerte de empaste final, para comprender las diferentes temperaturas de la opinión pública, y para lograr detectar los diversos aparatos de propaganda que se activaron y sus efectos en el mainstream del proceso de Contadora. Esta lectura incrementada debe incluir prensa y revistas no académicas de divulgación política.

\section{Estudio de caso}

Ámbito historiográfico: Guerra Fría (1947-1991).

Región de estudio dentro del sistema internacional: Centroamérica.

Tiempo histórico del estudio de caso: 1952-1954. 
Documentación: Archivos Nacionales de Estados Unidos. Colección archivística: Foreign Relations of the United States, 1952-1954, Guatemala ${ }^{3}$

Problema: Guatemala en el vórtice de la primera Guerra Fría mundial.

Países involucrados en el estudio de caso: Guatemala, Estados Unidos, Nicaragua, Honduras y Checoslovaquia.

Agentes involucrados: Gobierno de Guatemala, Nicaragua y Estados Unidos, la empresa United Fruit Company, Departamento de Estado, Agencia Central de Información (CIA), Ejército de Guatemala, fuerzas rebeldes mixtas, cuerpo diplomático destacado en Ciudad de Guatemala.

Acontecimientos políticos, militares y de inteligencia para la problematización de la investigación: El gobierno de Arbenz ha transcurrido en medio de "disturbios laborales", según informa la inteligencia estadounidense, lo cual puede conducir hacia "una posible sovietización de Guatemala" por lo que se ha establecido una red de conspiraciones contra el gobierno de Jacobo Arbenz, electo en el año de 1951.

El actor principal de la trama es el excoronel del ejército guatemalteco Carlos Castillo Armas, exiliado en Honduras. Los rebeldes cuentan con el apoyo de Anastasio Somoza de Nicaragua y de la United Fruit Company.

En 1952 la Agencia Central de Información (CIA) está alarmada por la cada vez mayor dependencia logística de Arbenz con el Partido Comunista de Guatemala. Esta situación ha hecho que agentes de la CIA retomen el contacto con Castillo Armas. La documentación aclara que la CIA ha detenido su apoyo a Castillo Armas durante el mes de octubre de 1952, pues se ha filtrado información sobre la intervención de Estados Unidos en una posible invasión a Guatemala.

\footnotetext{
Todos los datos de este estudio de caso han sido extraídos de la colección Relaciones Exteriores de los Archivos Nacionales, gracias a Ley Pública 102-138 (Ley de Autorización de Relaciones Exteriores de 1992 y 1993) firmada por el presidente George Bush el 28 de octubre de 1991. La Sección 198 agregó un Título IV a la Ley de Autoridades Básicas del Departamento de Estado de 1956. El estatuto exige que la serie de Relaciones Exteriores sea "un registro exhaustivo, preciso y confiable de las principales decisiones de política exterior de los Estados Unidos" que describa la valiosa actividad diplomática de los Estados Unidos durante los años del estudio de caso (1952-1954).
} 
El presidente Ike Eisenhower ha retomado interés en el asunto de Guatemala, dado que el 12 de agosto de 1953, Arbenz ha revelado el segundo proceso de expropiación de tierras de la United Fruit Company. El mismo 12 de agosto la Junta Coordinadora de Operaciones ha autorizado a la CIA tomar acciones "sobre una base de alta prioridad" en el proyecto PBSUCCESS (criptónimo usado por la CIA).

Con el auxilio económico de tres millones de dólares la CIA ha entrenado grupos rebeldes comandados por Castillo Armas y ha retomado contactos con oficiales del ejército guatemalteco esperanzados en deponer el gobierno de Arbenz desde adentro.

LA CIA ha tenido acceso a cierta información sobre posibles alianzas del gobierno de Arbenz con países miembros del Pacto de Varsovia, violando la integridad y la seguridad hemisférica con la intervención de una potencia foránea en los asuntos latinoamericanos.

Los informen no se equivocan: un barco de bandera sueca llevaba armamento proveniente de Checoslovaquia, y ha atracado en un puerto de Guatemala durante la primavera de 1954. El Departamento de Estado estadounidense usará este hecho para prevenir a los oficiales del ejército guatemalteco, de que su comandante en jefe intenta constituir una milicia popular, bajo la disciplina política del partido, y así anular el rol y el poder de fuego del ejército contra la revolución arbencista.

Desenlace: Castillo Armas a la cabeza de una pequeña fuerza rebelde ha invadido desde Honduras. El 18 de junio de 1954 los rebeldes han entrado a Guatemala en una dinámica de escaramuzas sin ninguna victoria concluyente contra las fuerzas leales de Arbenz.

Ha sido necesaria la puesta en marcha del sistema diplomático público estadounidense (propaganda), junto con dispositivos de presión diplomática. Al mismo tiempo se ha llevado una ofensiva aérea de pilotos veteranos de la Segunda Guerra Mundial y pilotos empleados por la CIA, con el objetivo de generar un ambiente caótico alrededor de Arbenz y de sus oficiales leales.

Una vez activada la red entre la CIA y oficiales guatemaltecos, se han otorgado garantías a los de mayor cercanía con Arbenz para que lo hagan 
renunciar. La renuncia se obtuvo el 27 de junio de 1954. Seguidamente diplomáticos estadounidenses apostados en Ciudad de Guatemala y agentes de la CIA, han servido de canal para las negociaciones entre Castillo Armas y los oficiales que dieron el golpe final contra Arbenz.

Pertinencia del estudio de caso para la historia de las RI: el derrocamiento del gobierno de Jacobo Arbenz en Guatemala (1954) ha sido un hecho histórico manipulado por sectores políticos e intelectuales, que han exagerado el papel imperialista o neocolonizador de Estados Unidos en América Latina, y subestimado el rol intervencionista y saboteador de la Unión Soviética por sí misma o a través de su satélite cubano. Como advierte Tertrais (2018): "La humillación histórica se ha convertido en un argumento habitual de las relaciones internacionales, incluso para entender el yihadismo" (p.18), no solo el yihadismo, sino los nuevos relatos ideológicos autoritarios de América Latina como fórmula para tolerar el castrismo y su dimensión regional, que tanto daño ha hecho a la cultura política latinoamericana (Verba \& Almond, 1963).

\section{Palabras clave}

Historia de las Relaciones Internacionales, Historiografía, Historia de la Guerra Fría, Institucionalismo Histórico, Realismo, Realismo neoclásico, Sistema Internacional, Archivos.

\section{Conclusiones}

A lo largo de este tour d' horizon de la historia de las Relaciones Internacionales, se intentó otra estética narrativa, acaso variada, para lograr mayores contrastes en los problemas que sugiere el área. Asimismo, se quiso realizar un capítulo no solo con utilidad dentro del debate epistemológico de la historia de las Relaciones Internacionales, sino con un epígrafe metodológico, como suerte de modelo -fruto de nuestra experiencia historiográfica- para investigadores en la disciplina.

Estamos al tanto de la diversidad de propuestas que existen en estas zonas del conocimiento, en donde todas pueden valer, siempre y cuando sean sólidas en el proceso de investigación documental, coherentes en el abordaje del objeto de estudio, con un aparato crítico consistente, una pro- 
puesta metodológica eficiente, con resultados útiles para el aporte científico y académico. Esta es una propuesta entre muchas, que su máxima aspiración es la conveniencia instrumental y la justificación racional con los temas que le atañe: historia de las Relaciones Internacionales y la historia para las Relaciones Internacionales.

\section{Bibliografía}

Amenta, Edwin (2000). "What We Know about the Development of Social Policy: Comparative and Historical Research at the Crossroads." [Paper presented at the Conference on Comparative-Historical Analysis, Harvard University.]

Barbe, Esther (2003). Relaciones Internacionales, Tecnos, Madrid.

Barbe, Esther (1986). La obra y el pensamiento de Hans Morgenthau, Universidad Complutense de Madrid.

Burke, Peter (2007). The French Historical Revolution: Annales School 1929-1989, Polity Press, Oxford.

Bloch, Marc (2001). Apología para la historia o el oficio de historiador. México D.F.: Fondo de Cultura Económica.

Brag, William (1981). Eisenhower the President: Crucial Days 1951-1960, New Jersey: Prentice-Hall.

Cabrera García, Ernesto. (2014). "La invención del realismo político: Un ejercicio de historia conceptual". Signos filosóficos, 16(32), 126-149. Recuperado en 24 de febrero de 2020, de http://www.scielo.org.mx/scielo.php?script=sci_arttext \&pid=S1665-13242014000200005\&lng $=$ es\&tlng $=$ es.

Cardozo Uzcátegui, Alejandro (2019). "La Guerra Fría en el marco de una epistemología de la historia contemporánea venezolana", en Cardozo Uzcátegui, Alejandro, Luis Ricardo Dávila y Edgardo Mondolfi Gudat (eds. acad.), Guerra Fría, Política Petróleo y Lucha Armada, Bogotá, Universidad del Rosario, pp. 1-31.

Carr, Edward Hallet (2004). La crisis de los veinte años (1919-1939). Una introducción al estudio de las relaciones internacionales, Madrid: Catarata.

Cascante, Carlos (2015). "Historia, Historiografía y Relaciones Internacionales: encuentros y desencuentros entre Clío y Tucídides", en Ciencias Sociales y Relaciones Internacionales. Nuevas perspectivas desde América Latina, San José de Costa Rica, Flacso-UNA.

Hobson, J. (2002). "What's at stake in "bringing historical sociology back into international relations"? Transcending "cronofetishism" and "tempocentrism" 
in international relations". En Hobden, S. y Hobson, J. Historical Sociology of International Relations, Reino Unido, Cambridge University Press.

Gaddis, John (2011). Nueva Historia de la Guerra Fría, México: FCE.

Gilpin Robert (1984). "The richness of the tradition of political realism", en International Organization, v. 38, n. 2, pp. 290-319.

Hobsbawm, Eric (1994). The Age of Extremes: A History of the World, 1914-1991, Nueva York: Pantheon Books.

Johnson, Paul (2007). Estados Unidos. La historia, Madrid, Barataria.

Krippendorff, Ekkehart (1996). El sistema internacional como historia: introducción a las relaciones internacionales. México, Fondo de Cultura Económica.

Keohane Robert and Nye Joseph (1973). Transnational Relations and World Politics, Harvard U. P., Cambridge.

Keohane Robert (1977). Power and interdependance: World Politics in Transition, Little Brown and Company, Boston.

Keohane Robert (1984). After Hegemony. Cooperation and Discord in the World Political Economy, Princeton U. P., Princeton.

Keohane, Robert (1983). "Theory of World Politics: Structural realism and beyond", en A. W. Finter (ed.): Political Science: The State of the Discipline, APSA, Washington D.C., 1983, p. 504 .

Kissinger, Henry (2000). La Diplomacia, México: FCE.

Lewkowicz, Nicolas (2010). The German Question and the International Order, 1943-48, Nueva York, Palgrave Macmilliam. Mailer, Norman (2008 [c.1968]). Los ejércitos de la noche, Anagrama, Barcelona.

Mahoney, James (2000). "Path Dependence in Historical Sociology", en Theory and Society, 29 (4): 507-548.

Mijares, Víctor M y Alejandro Cardozo Uzcátegui (2020). "Militares bajo control: Fallas teóricas detrás del estancamiento de Juan Guaidó”, en Foreign Affairs Latinoamérica, 2 (2)

Morgenthau, Hans (1972). Politics among Nations. The Struggle for Power and Peace, Nueva York, Alfred A. Knopf Inc.

Morgenthau, Hans (1962). Politics in the Twentieth Century, Chicago, University of Chicago Press.

Neila Hernández, José Luis (2001). "La Historia de las Relaciones Internacionales: Notas para una aproximación historiográfica”, en Ayer, 42, 17-42. 
Pomian Krysztof (1978). "Impact of the Annales School in Eastern Europe", Review (Fernand Braudel Center), [The Impact of the "Annales" School on the Social Sciences], 1 (3/4): 101-121

Pierson y Theda Skocpol (2008). "El Institucionalismo Histórico en la Ciencia Política Contemporánea" en Revista Uruguaya de Ciencia Política, 17 (1): 7-38.

Ramos Jiménez, Alfredo (1997). Las formas modernas de la politica. Estudio sobre la democratización de América Latina, Mérida, Centro de Investigaciones de Política Comparada.

Renouvin, Pierre (1998). Historia de las Relaciones Internacionales (siglos XIX y XX), Madrid, Akal.

Ripsman, Norrin M., Jeffrey W. Taliaferro, and Steven E. Lobell (2016). Neoclassical Realist Theory of International Politics. Oxford University Press.

Rosoux, Valérie-Barbara (2000). Les Usages de la mémorie dans les relations internationales. Bruselas, Bruylant.

Stonor Saunders, Frances (2001). La CIA y la Guerra Fría cultural, Madrid, Debate.

Taylor, A. J. P. (1996). Origin of the Second World War. New York, Simon and Schuster.

Tertrais, Bruno (2018). La venganza de la historia. Madrid, RBA.

Verba, S. and Gabriel Almond. (1963). The Civic Culture: Political Attitudes and Democracy in Five Nations. Nueva Jersey, Princeton University Press.

Waltz, Kenneth (1959), Man, the State and War. A Theoretical Analysis, Nueva York, Columbia University Press. 